\title{
IMPLEMENTASI METODE ANALITYCAL HIERARCHY PROCESS (AHP) DAN TOPSIS UNTUK PEMILIHAN KAMERA
}

\author{
Roby Muhammad Ikhsan ${ }^{1}$,Dr.Septi Andryana, S.Kom.,MMSI ${ }^{2}$,Andrianingsih S.Kom., \\ MMSI $^{3}$ \\ 1,2 Universitas Nasional; Jln Sawo Manila No 61, 0217806700 \\ ${ }^{3}$ Jurusan Sistem Informasi,FTKI, Jakarta \\ e-mail:1robimuhammad79@gmail.com, ${ }^{2}$ septi.andryana@ civitas.unas.ac.id, $\underline{3}$ andri \\ aningsih@civitas.unas..ac.id
}

\begin{abstract}
Abstrak
Dengan banyaknya varian kamera DSLR yang muncul, tentu tidak sedikit orang yang kesulitan dalam memilih perangkat. Banyak konsumen yang salah memilih kamera DSLR yang sesuai dengan kebutuhannya. Sistem pendukung keputusan sangat dibutuhkan dalam menangani persoalan tersebut. Sebuah aplikasi yang dirancang untuk membantu pengguna dalam mengambil keputusan dan dapat pula digunakan sebagai sebuah sistem rekomendasi pemilihan kamera DSLR bagi sebuah toko atau outlet kamera kepada pelanggan. Analytical Hierarchy Process (AHP) merupakan metode analitis untuk memecahkan masalah kuantitaf dan kualitatif yang fleksibel dan kuat, dapat juga dipakai mencari nilai bobot kriteria yang ada dalam penelitian ini. Metode TOPSIS dan AHP dikombinasikan dan implementasikan untuk menemukan kamera terbaik. Dalam pembobotan masing-masing kriteria menggunakan metode AHP kemudian analisis data untuk menentukan ranking kamera terbaik menggunakan metode TOPSIS. Proses pengambilan keputusan pada dasarnya adalah memilih suatu alternatif yang terbaik.
\end{abstract}

Kata kunci - DSLR, AHP, Topsis, SPK, Kamera, Website

\begin{abstract}
With so many DSLR cameras appearing, of course not a few people have difficulty choosing a device. Many consumers choose the wrong DSLR camera that suits their needs. Decision support system is needed in this problem. An application designed to assist users in making decisions and can also be used as a recommendation system for selecting a DSLR camera from a shop or camera outlet to customers. Analytical Hierarchy Process (AHP) is an analytical method for solving quantitative and qualitative problems that is flexible and robust, it can also be used to find the value of the criteria in this study. TOPSIS and AHP methods are combined and implemented to find the best camera. In weighting each criterion using the AHP method then data analysis to determine the best camera ranking using the TOPSIS method. The decision making process in a decision is to choose the best alternative
\end{abstract}

Keywords—DSLR, AHP, Topsis, SPK, Camera, Website 


\section{PENDAHULUAN}

Dengan banyaknya varian kamera DSLR yang muncul, tentu tidak sedikit orang yang kesulitan dalam memilih perangkat. Banyak konsumen yang salah memilih kamera DSLR yang sesuai dengan kebutuhannya. Permasalahan tersebut dapat menyebabkan terjadinya ketidakpuasan dalam pembelian kamera karena terjadi kesalahan pemilihan perangkat. Oleh karena itu, dibutuhkan sistem rekomendasi untuk menyelesaikan permasalahan bagi pengguna dalam proses pemilihan kamera DSLR. Dengan adanya system rekomendasi ini, maka dapat membantu pengguna dalam memilih kamera DSLR dengan kriteria yang diinginkan dan memberikan alternatif yang cocok untuk pengguna.

Kamera Digital Single Lens Reflex (DSLR) adalah kamera yang menggunakan sistem jajaran lensa jalur tunggal untuk melewatkan berkas cahaya menuju kedua tempat, yaitu Focal Plane dan View Finder, sehingga memungkinkan fotografer untuk melihat objek melalui kamera yang sama persis seperti hasil fotonya[2]. Seiring berkembangnya kamera pada era globalisasi sekarang ini, penerapan teknologi sangat dibutuhkan demi mendapatkan kriteria yang sesuai dengan kebutuhan fotografer.

Banyak sekali parameter yang dapat dijadikan tolak ukur bagi seseorang untuk menentukan kamera DSLR mana yang sesuai dengan kebutuhan dan keinginannya. Parameter tersebut dapat berupa penilaian subyektif atau penilaian objektif. Permasalahannya, terkadang seseorang mengalami kesulitan dalam menentukan parameter yang diambil untuk menentukan keputusan, sehingga pilihan yang diambil pada akhirnya tidak sesuai dengan apa yang diharapkan. Sistem pendukung keputusan sangat dibutuhkan dalam menangani persoalan tersebut. Sebuah aplikasi yang dirancang untuk membantu pengguna dalam mengambil keputusan dan dapat pula digunakan sebagai sebuah sistem rekomendasi pemilihan kamera DSLR bagi sebuah toko atau outlet kamera kepada pelanggan.

Analytical Hierarchy Process (AHP) merupakan metode analitis untuk memecahkan masalah kuantitaf dan kualitatif yang fleksibel dan kuat, dapat juga dipakai mencari nilai bobot kriteria yang ada dalam penelitian ini. Tetapi, metode Analytical Hierarchy Process (AHP) memiliki batasan pada jumlah perbandingan yang dipakai, sehingga memerlukan metode TOPSIS. Kemudian, pendekatan TOPSIS mempunya prosedur sederhana tetapi sistematis dalam hal perhitungan, konsep dasar dari pendekatan ini ialah melakukan pemilihan alternatif dari rute geometris terjauh dari solusi ideal negative dan rute geometris terpendek dari solusi ideal positif[3.]

Berbagai metode dalam sistem pendukung keputusan telah banyak yang dikombinasikan dengan metode AHP, salah satunya metode TOPSIS. Metode TOPSIS dan AHP dikombinasikan dan implementasikan untuk menemukan objek wisata terbaik di Pulau Bali. Dalam pembobotan masingmasing kriteria menggunakan metode AHP kemudian analisis data untuk menentukan ranking objek wisata terbaik menggunakan metode TOPSIS [4].

Untuk menentukan promosi jabatan metode AHP dan TOPSIS juga pernah diterapkan dan hasil dari penerapan kombinasi metode TOPSIS dan AHP sistem pendukung keputusan bisa membantu perusahaan dalam membuat keputusan promosi, untuk menghasilkan lebih banyak keputusan berdasarkan informasi dan berdampak pada kemajuan perusahaan. Dengan mempergunakan sistem keputusan TOPSIS dan AHP sistem pendukung dapat mempermudah perusahaan untuk membuat keputusan yang cukup tepat untuk menentukan promosi untuk karyawannya[5]. 
Proses pengambilan keputusan pada dasarnya adalah memilih suatu alternatif yang terbaik. Seperti melakukan penstrukturan persoalan, penentuan alternatif- alternatif, penenetapan nilai kemungkinan untuk variabel aleatori, penetap nilai, persyaratan preferensi terhadap waktu, dan spesifikasi atas resiko. Betapapun melebarnya alternatif yang dapat ditetapkan maupun terperincinya penjajagan nilai kemungkinan, keterbatasan yang tetap melingkupi adalah dasar pembandingan berbentuk suatu kriteria yang tunggal.

Agar dapat memberikan solusi terhadap suatu pemasalahan yang telah diuraikan tersebut maka penulis membuat "Implementasi Metode Analytical Hierarchy Process (AHP) Dan TOPSIS Untuk Pemilihan Kamera“. 


\section{METODE PENELITIAN}

Penelitian ini dilaksanakan dengan teknik interview untuk mengumpulkan data yang diperlukan serta melakukan kajian pustaka untuk mendukung dalam pengambilan hasil penelitian.

Tahapan dalam penelitian dapat diuraikan seperti berikut ini :

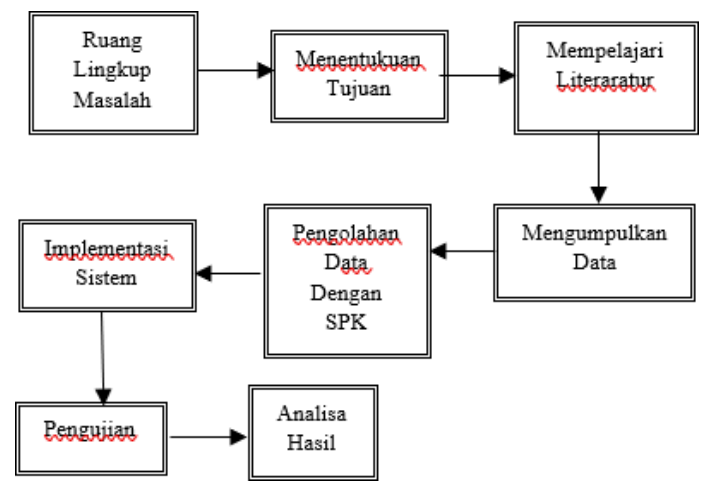

1. Ruang Lingkup Masalah

Pada penelitian yang dilakukan ini memiliki ruang lingkup seperti berikut :

a. Sistem ditujukan untuk calon pembeli atau pencari kamera DSLR.

b. Sistem yang akan dibangun berbasis website.

c. Data yang digunakan adalah data kamera DSLR yang bersifat umum seperti harga, fitur,resolusi dan baterai sebagai bahan (kriteria) yang dipertimbangkan.

d. Metode yang digunakan adalah Analytical Hierarchy Process (AHP) dan TOPSIS

\section{Implementasi Sistem}

Implementasi sistem ini berguna agar mempermudah pada saat pembuktian hasil analisa yang sebelumnya dilakukan.

\section{Pengujian}

Pada tahap ini dilakukan proses pengujian atau testing terhadap sistem yang telah dibangun sebelumnya.

\section{Menentukan Tujuan}

Dari masalah yang dipahami, maka sudah ditentukan tujuan yang harus dicapai dalam penelitian ini. Tujuan ini menilai target yang dicapai, khususnya yang dapat menanggulangi permasalahan yang ada. Untuk mengetahui kriteria yang tepat dalam pemilihan kamera DSLR agar tidak terjadi kesalahan memilih kamera DSLR.

\section{Mempelajari Literatur}

Agar mencapai tujuan, maka dipelajari sejumlah literatur yang dapat digunakan. Kemudian literatur yang telah dipelajari itu dipilih agar dapat ditentukan literatur apa saja yang akan digunakan dalam penelitian. Literatur diambil dari internet, yang berupa tulisan dan jurnal ilmiah tentang Sistem pendukung keputusan metode Analitycal Hierarchy Process (AHP) dan TOPSIS beberapa buku yang mendukung penelitian.

\section{Mengumpulkan Data}

Untuk pengumpulan data dilaksanakan wawancara yang bertujuan guna mendapatkan informasi atau data yang dibutuhkan. Kemudian dilakukan observasi yaitu pengamatan secara langsung ditempat riset sehingga persoalan yang ada bisa diketahui secara jelas. 


\section{Pengolahan Data Dengan SPK}

Dengan menilai masalah yang sudah dianalisis, maka diinginkan masalah dapat dicerna dengan baik.Pada analisa masalah ini menggambarkan proses pengambilan keputusan dalam pemilihan konsentrasi program studi. Metode analisa DSS yang dipakai untuk menganalisis kebutuhan dalam mengambil keputusan yang optimal telah ditetapkan dengan menggunakan kriteria-kriteria yang telah ditentukan. Metode SPK yang digunakan adalah AHP dan TOPSIS.

\section{Analisa Hasil}

Analisa hasil menurut perhitungan TOPSIS dan Analitycal Hierarchy Process (AHP), analisis hasil dari sistem yang dibangun sehingga didapatkan hasil keputusan yang digunakan untuk pengambilan keputusan dalam pemilihan kamera DSLR terbaik.

\subsection{Sistem Pendukung Keputusan}

Konsep Sistem Pendukung Keputusan (SPK) atau Decision Support System (DSS) definisi awalnya adalah suatu sistem yang ditunjukan untuk mendukung manajemen pengambilan keputusan. Sistem Pendukung Keputusan (Decision Support System) merupakan suatu pendekatan untuk mendukung pengambilan keputusan.[6]

\subsection{Metode TOPSIS}

Metode TOPSIS pertama kali diperkenalkan oleh Hwang dan Yoon pada tahun 1981. Dalam metode ini memiliki dua alternatif buatan yang dihipotesiskan, satu adalah ideal penyelesaian, dan yang lainnya adalah penyelesaian ideal negatif. Dasar prinsip dari metode TOPSIS ialah alternatif yang dipilih harus memiliki jarak terdekat dari penyelesaian ideal positif dan jarak terjauh dari penyelesaian ideal negatif .[7]

\subsection{Metode Analitycal Hierarchy Process (AHP)}

Metode Analytic Hierarchy Process (AHP) adalah metode efektif yang cocok untuk mendekati MCDM terkait dengan membuat pilihan dari beberapa alternatif dan yang menyediakan perbandingan opsi yang dipertimbangkan. AHP bertujuan untuk mengintegrasikan langkah-langkah yang berbeda ke dalam skor keseluruhan tunggal untuk alternatif keputusan peringkat. Atribut utamanya adalah bahwa ia didasarkan pada penilaian perbandingan berpasangan.[7]. 


\section{METODE PENELITIAN}

A. Analisis Masalah

Tabel 1 Analisis Sebab Akibat

\begin{tabular}{|c|c|c|c|}
\hline \multicolumn{2}{|c|}{$\begin{array}{c}\text { Analisis Penyebab Dan } \\
\text { Akibat }\end{array}$} & \multicolumn{2}{|c|}{$\begin{array}{l}\text { Tujuan Memperbaiki } \\
\text { Sistem }\end{array}$} \\
\hline Masalah & $\begin{array}{l}\text { Penyebab } \\
\text { dan Akibat }\end{array}$ & $\begin{array}{l}\text { Tujuan } \\
\text { Sistem }\end{array}$ & $\begin{array}{l}\text { Batasan } \\
\text { Sistem }\end{array}$ \\
\hline $\begin{array}{l}\text { Calon pembeli kamera } \\
\text { DSLR } \\
\text { kesulitan dalam } \\
\text { menentuka n pilihan } \\
\text { kamera yang akan dibeli }\end{array}$ & $\begin{array}{l}\text { Sebab : calon } \\
\text { pembeli DSLR } \\
\text { kesulitan Ketika } \\
\text { membanding kan } \\
\text { spesifikasi- spesifikasi } \\
\text { antar kamera DSLR } \\
\quad \text { satu dengan } \\
\text { DSLR yang lainnya. } \\
\text { Akibat : Spesifikasi } \\
\text { yang telah dibeli } \\
\text { didak sesuai } \\
\text { dengan kebutuhan } \\
\text { konsumen }\end{array}$ & $\begin{array}{l}\text { Memberik an rekomenda } \\
\text { si kepada calon } \\
\text { pembeli kamera DSLR } \\
\text { Sebagai bahan } \\
\text { pertimbang an dalam } \\
\text { memilih kamera DSLR }\end{array}$ & $\begin{array}{l}\text { Kriteria yang digunaka n dalam } \\
\text { memilih kamera DSLR } \\
\text { adalah harga, fitur, tahun, } \\
\text { resolusi, dandaya tahan baterai. }\end{array}$ \\
\hline $\begin{array}{l}\text { Kesulitan dalam } \\
\text { mendapatk an } \\
\text { rekomenda si dalam } \\
\text { memilih kamera DSLR }\end{array}$ & $\begin{array}{l}\text { Sebab : belum } \\
\text { adanya sistem untuk } \\
\text { membantu dalam } \\
\text { memberikan } \\
\text { rekomendasi pemilihan } \\
\text { kamera DSLR } \\
\text { Akibat :pembeli } \\
\text { kamera DSLR tidak } \\
\text { mendapatka n kamera } \\
\text { DSLR yang sesuai } \\
\text { dengan spesifikasi } \\
\text { yang dibutuhkan }\end{array}$ & $\begin{array}{l}\text { Memudahk an calon } \\
\text { pembeli mendapatk an } \\
\text { informasi mengenai } \\
\text { kamera DSLR } \\
\text { serta mencari rekomenda } \\
\text { si dalam pemilihan } \\
\text { kamera DSLR } \\
\text { yang akan dibeli }\end{array}$ & $\begin{array}{l}\text { Sistem yang dibuat berbasis } \\
\text { web yang memung kinkan calon } \\
\text { pembeli kamera DSLR } \\
\text { bisa dengan mudah mengaks } \\
\text { esnya. }\end{array}$ \\
\hline
\end{tabular}




\section{Implementasi AHP-TOPSIS}

Kriteria penentuan pemilihan kamera $D S L R$ yang akan jadi dasar untuk perhitungan mesti dimasukkan dalam sistem dilihat pada gambar di bawah ini :

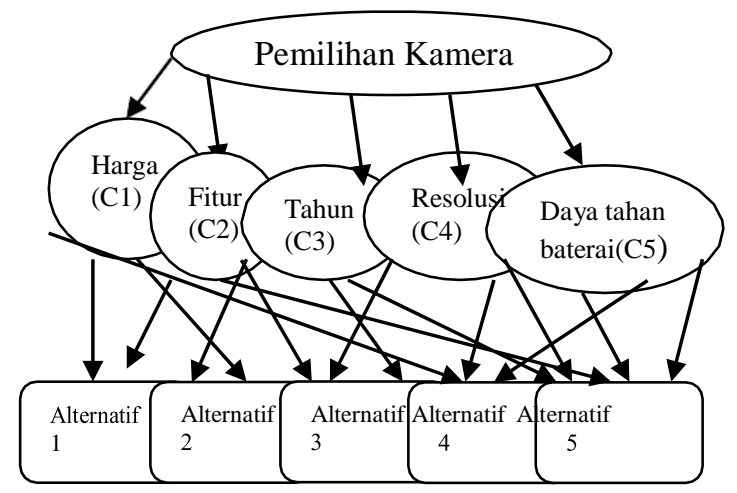

Kriteria yang digunakan pada SPK Proses penghitungan dari rekomendasi kamera mirrorles dengan metode AHPTOPSIS dimulai dengan memberikan penilaian. Nilai "B" akan diberi prioritas 1, nilai "CB" akan diberi prioritas 2, dan nilai "KB" akan diberi prioritas 3. Langkah pertama bentuk sebuah matriks berupatabel pairwise comparison (nilai perbandingan berpasangan) yang dapat dilihat pada table 2 berikut ini:

Tabel 2. Tabel matriks keputusan perbandingan berpasangan 1

\begin{tabular}{|l|l|l|l|l|l|}
\hline Kriteria & C1 & C2 & C3 & C4 & C5 \\
\hline C1 & 1 & 5 & 6 & 4 & 3 \\
\hline C2 & $1 / 5$ & 1 & 9 & 8 & 7 \\
\hline C3 & $1 / 6$ & $1 / 9$ & 1 & 6 & 7 \\
\hline C4 & $1 / 4$ & $1 / 8$ & $1 / 6$ & 1 & 7 \\
\hline C5 & $1 / 3$ & $1 / 7$ & $1 / 7$ & $1 / 7$ & 1 \\
\hline
\end{tabular}

Keterangan :

$\mathrm{C} 1=$ Harga $\mathrm{C} 2=$ Fitur $\mathrm{C} 3=$ Tahun

$\mathrm{C} 4=$ Resolusi

C5 = Daya tahan baterai

Tahapan kedua ubah matriks perbandingan berpasangan itu kebentuk decimal dan jumlahkan tiap kolom tersebut yang dapat dilihat pada table 3, dalam perhitungan ini penulis memakai 3 angka dibelakang koma.

\begin{tabular}{|l|l|l|l|l|l|}
\hline Kriteria & C1 & C2 & C3 & C4 & C5 \\
\hline C1 & 1,000 & 5,000 & 6,000 & 4,000 & 3,000 \\
\hline C2 & 0,200 & 1,000 & 9,000 & 8,000 & 7,000 \\
\hline C3 & 0,166 & 0,111 & 1,000 & 6,000 & 7,000 \\
\hline
\end{tabular}


Tabel 3. Tabel matriks

\begin{tabular}{|l|l|l|l|l|l|}
\hline C4 & 0,250 & 0,125 & 0,166 & 1,000 & 7,000 \\
\hline C5 & 0,333 & 0,142 & 0,142 & 0,142 & 1,000 \\
\hline
\end{tabular}

berpasangan 2

Matrik diatas akan dievaluasi dan dijumlahkan setiap kolomnya sehingga diperoleh hasil seperti di bawah ini :

Kolom C1 $=1,000+0,200+0,166+0,250+0,333=1,949$ Selanjutnya menghitung semuanya sampai kolom C5. Setelah jumlah kolom ditentukan, maka tahapan selanjutnya ialah membagi angka-angka pada tabel 2 dengan jumlah tiap kolomnya, hingga terbentuk matrik normalisasi. Kolom $\mathrm{C} 1$, baris $\mathrm{C} 1$ dibagi jumlah kolom $\mathrm{C} 1=$ $1,000 / 1,949=0,513$

Lanjutkan perhitungan itu pada semua angka pada tabel 3. Dan hasilnya dapat dilihat pada tabel 4 berikut ini :

Tabel 4.Tabel matriks keputusan ternormalisasi

\begin{tabular}{|l|l|l|l|l|l|}
\hline Kriteria & C1 & C2 & C3 & C4 & C5 \\
\hline C1 & 0,513 & 0,784 & 0,368 & 0,209 & 0,120 \\
\hline C2 & 0,102 & 0,157 & 0,552 & 0,418 & 0,280 \\
\hline C3 & 0,085 & 0,017 & 0,061 & 0,313 & 0,280 \\
\hline C4 & 0,128 & 0,020 & 0,010 & 0,052 & 0,280 \\
\hline C5 & 0,170 & 0,022 & 0,009 & 0,007 & 0,040 \\
\hline
\end{tabular}

Tahapan selanjutnya mencari skala mutu prioritas, dengan mencari rata-rata baris dari tabel 3, dan perhitungannya ialah sebagai berikut:

Rata-rata baris $\mathrm{C} 1=(0,513+0,784+0,368+0,209+0,120) / 5=0,39$

Selanjutnya menghitung baris tersebut sampai baris C5, dan hasilnya dpat dilihat dari tabel dibawah ini :

Tabel 5. Tabel matriks bobot prioritas

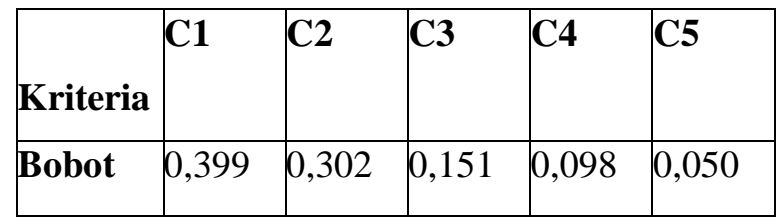

Konsistensi matrik diperoleh dari perkalian tabel 4 dengan tabel bobot 5 .

Konsistensi $=(0,51 * 0,399)+(0,784 * 0,302)+(0,368 * 0,151)+(0,209 * 0,098)+(0,120 * 0,050)$

$=3,359$

Selanjutnya menghitung baris tersebut hingga baris C5, dan hasilnya dapat dilihat dari tabel dibawah ini : 
Tabel 6. Tabel Matriks Konsistensi

\begin{tabular}{|c|c|}
\hline Kriteria & Hasil \\
\hline C1 & 3,359 \\
\hline C2 & 2,878 \\
\hline C3 & 1,188 \\
\hline C4 & 0,610 \\
\hline C5 & 0,261 \\
\hline
\end{tabular}

Kemudian tahapan selanjutnya ialah mencari konsistensi dengan persamaan 4 dan 5. Untuk mencari konsistensi mutu yang diperoleh dipakai persamaan 4 dan 5, diperoleh dari hasil

penjumlahan hasil untuk antara jumlah tiap baris dengan prioritasnya dari tabel 6 diatas. Sehingga didapat sebesar 7,451 dan dengan persamaan 3 didapat nilai CI sebagai berikut:

Sehingga didapat sebesar 7,451 dan dengan persamaan 3 didapat nilai CI sebagai berikut:

$C I=\frac{\lambda \max -\mathrm{n}}{\mathrm{n}-1}=\frac{7,451-5}{5-1}=\frac{2,451}{4}=0,61275$

Kemudian dihitung CR (uji konsistensi) dengan persamaan 4, dan didapat nilai CR sebagai berikut:

$C R=\frac{C I}{R I}=\frac{0,61275}{1,12}=0,547093$

Nilai RI didapat dari table 1 dimana ukuran matriksnya ialah 5x5, sebab ada 5 kriteria yang dipakai. Hasil nilai dari pengujian konsistensi diatas mengindikasikan bahwa $\mathrm{CR}<=0.1$ maka mutu prioritas diatas telah konsisten dan bisa melanjutkan ke metode TOPSIS guna merangking pemiilihan kamera mirorrles yang cocok dengan keperluan user.

tiap kolom tersebut yang dapat dilihat pada table 3, dalam perhitungan ini penulis memakai 3 angka dibelakang koma.

Tabel 3. Tabel matriks keputusan perbandingan berpasangan 2

\begin{tabular}{|l|l|l|l|l|l|}
\hline Kriteria & C1 & C2 & C3 & C4 & C5 \\
\hline C1 & 1,000 & 5,000 & 6,000 & 4,000 & 3,000 \\
\hline C2 & 0,200 & 1,000 & 9,000 & 8,000 & 7,000 \\
\hline C3 & 0,166 & 0,111 & 1,000 & 6,000 & 7,000 \\
\hline C4 & 0,250 & 0,125 & 0,166 & 1,000 & 7,000 \\
\hline C5 & 0,333 & 0,142 & 0,142 & 0,142 & 1,000 \\
\hline
\end{tabular}

Matrik diatas akan dievaluasi dan dijumlahkan setiap kolomnya sehingga diperoleh hasil seperti di bawah ini :

Kolom C1 $=1,000+0,200+0,166+0,250+0,333=1,949$

Selanjutnya menghitung semuanya sampai kolom C5. Setelah jumlah kolom ditentukan, maka tahapan selanjutnya ialah membagi angka-angka pada tabel 2 dengan jumlah tiap kolomnya, hingga terbentuk matrik normalisasi. 
Kolom C1, baris C1 dibagi jumlah kolom $\mathrm{C} 1=1,000 / 1,949=0,513$

Lanjutkan perhitungan itu pada semua angka pada tabel 3. Dan hasilnya dapat dilihat pada tabel 4 berikut ini :

Tabel 4.Tabel matriks keputusan ternormalisasi

\begin{tabular}{|l|l|l|l|l|l|}
\hline Kriteria & C1 & C2 & C3 & C4 & C5 \\
\hline C1 & 0,513 & 0,784 & 0,368 & 0,209 & 0,120 \\
\hline C2 & 0,102 & 0,157 & 0,552 & 0,418 & 0,280 \\
\hline C3 & 0,085 & 0,017 & 0,061 & 0,313 & 0,280 \\
\hline C4 & 0,128 & 0,020 & 0,010 & 0,052 & 0,280 \\
\hline C5 & 0,170 & 0,022 & 0,009 & 0,007 & 0,040 \\
\hline
\end{tabular}

Tahapan selanjutnya mencari skala mutu prioritas, dengan mencari rata-rata baris dari tabel 3, dan perhitungannya ialah sebagai berikut:

Rata-rata baris $\mathrm{C} 1=(0,513+0,784+0,368+0,209+0,120) / 5=0,399$

Selanjutnya menghitung baris tersebut sampai baris C5, dan hasilnya dapat dilihat dari tabel dibawah ini :

Tabel 5. Tabel matriks bobot prioritas

\begin{tabular}{|l|l|l|l|l|l|}
\hline Kriteria & C1 & C2 & C3 & C4 & C5 \\
\hline Bobot & 0,399 & 0,302 & 0,151 & 0,098 & 0,050 \\
\hline
\end{tabular}

Konsistensi matrik diperoleh dari perkalian tabel 4 dengan tabel bobot 5 .

Konsistensi $=(0,51 * 0,399)+(0,784 * 0,302)+(0,368 * 0,151)+(0,209 * 0,098)+(0,120 * 0,050)=3,359$

Selanjutnya menghitung baris tersebut hingga baris $\mathrm{C} 5$, dan hasilnya dapat dilihat dari tabel dibawah ini :

Tabel 6. Tabel Matriks Konsistensi

\begin{tabular}{|c|c|}
\hline Kriteria & Hasil \\
\hline C1 & 3,359 \\
\hline C2 & 2,878 \\
\hline C3 & 1,188 \\
\hline C4 & 0,610 \\
\hline C5 & 0,261 \\
\hline
\end{tabular}

Kemudian tahapan selanjutnya ialah mencari konsistensi dengan persamaan 4 dan 5. Untuk mencari konsistensi mutu yang diperoleh dipakai persamaan 4 dan 5, diperoleh dari hasil

penjumlahan hasil untuk antara jumlah tiap baris dengan prioritasnya dari tabel 6 diatas. Sehingga didapat sebesar 7,451 dan dengan persamaan 3 didapat nilai CI sebagai berikut:

$C I=\frac{\lambda \max -\mathrm{n}}{\mathrm{n}-1}=\frac{7,451-5}{5-1}=\frac{2,451}{4}=0,61275$ 
Kemudian dihitung CR (uji konsistensi) dengan persamaan 4, dan didapat nilai CR sebagai berikut:

$C R=\frac{C I}{R I}=\frac{0,61275}{1,12}=0,547093$

Nilai RI didapat dari table 1 dimana ukuran matriksnya ialah $5 \times 5$, sebab ada 5 kriteria yang dipakai. Hasil nilai dari pengujian konsistensi diatas mengindikasikan bahwa $\mathrm{CR}<=0.1$ maka mutu prioritas diatas telah konsisten dan bisa melanjutkan ke metode TOPSIS guna merangking pemiilihan kamera mirorrles yang cocok dengan keperluan user.

Dalam metode TOPSIS ini memiliki dua alternatif buatan yang dihipotesiskan, satu adalah ideal penyelesaian, dan yang lainnya adalah penyelesaian ideal negatif. Dasar prinsip dari metode TOPSIS ialah alternatif yang dipilih harus memiliki jarak terdekat dari penyelesaian ideal positif dan jarak terjauh dari penyelesaian ideal negatif. Kriteria dalam menilai pemilihan kamera ialah sebagai berikut:

$\mathrm{C} 1=$ Harga $\mathrm{C} 2=$ Fitur $\mathrm{C} 3=$ Tahun

$\mathrm{C} 4=$ Resolusi

C5 = Daya tahan baterai

Rangking kecocokan setiap alternatif pada setiap kriteria, dinilai dengan 1 sampai 5. Tabel berikut menunjukan rangking kecocokan dari setiap alternatif pada setiap kriteria :

Tabel 7. Rangking Kecocokan Alternatif

\begin{tabular}{|c|c|c|c|c|c|}
\hline Alternatif & C1 & C2 & C3 & C4 & C5 \\
\hline $\begin{array}{c}\text { Alternatif } \\
1\end{array}$ & 2 & 4 & 3 & 3 & 5 \\
\hline $\begin{array}{c}\text { Alternatif } \\
2\end{array}$ & 4 & 3 & 4 & 5 & 1 \\
\hline $\begin{array}{c}\text { Alternatif } \\
3\end{array}$ & 5 & 3 & 4 & 2 & 3 \\
\hline $\begin{array}{c}\text { Alternatif } \\
4\end{array}$ & 3 & 5 & 3 & 2 & 4 \\
\hline $\begin{array}{c}\text { Alternatif } \\
5\end{array}$ & 4 & 5 & 4 & 5 & 2 \\
\hline
\end{tabular}

Setelah rangking kecocokan diisikan maka selanjutnya menghitung normalisasi matriks menggunakan persamaan5. $r=\sqrt{2^{2}+4^{2}+5^{2}+3^{2}+4^{2}}=8,366$ Selanjutnya menghitung baris tersebut hingga baris $\mathrm{C} 5$, dan hasilnya dapat dilihat dari tabel dibawah ini :

Tabel 8. Hasil Jumlah Akar Pangkat

\begin{tabular}{|l|l|l|l|l|l|}
\hline Alternatif & C1 & C2 & C3 & C4 & C5 \\
\hline$R$ & 8,366 & 9,165 & 8,124 & 8,185 & 7,416 \\
\hline
\end{tabular}

Matrik normalisasi diperoleh dari pembagian tabel 7 dengan tabel 8. Contoh perhitungannya adalah sebagai berikut: Nilai kolom $\mathrm{C} 1$ baris $\mathrm{C} 1=2 / 8,366=0.7809$

\begin{tabular}{|l|l|l|l|l|l|}
\hline Alternatif & C1 & C2 & C3 & C4 & C5 \\
\hline Alternatif 1 & 0,239 & 0,436 & 0,369 & 0,367 & 0,674 \\
\hline
\end{tabular}




\begin{tabular}{|l|l|l|l|l|l|}
\hline Alternatif 2 & 0,478 & 0,327 & 0,492 & 0,611 & 0,135 \\
\hline Alternatif 3 & 0,598 & 0,327 & 0,492 & 0,244 & 0,405 \\
\hline Alternatif 4 & 0,359 & 0,546 & 0,369 & 0,244 & 0,539 \\
\hline Alternatif 5 & 0,478 & 0,546 & 0,492 & 0,611 & 0,270 \\
\hline
\end{tabular}

Tabel 9. Matrik Normalisasi

Selanjutnya matrik yang telah dinormalisasi maka akan dilakukan pembuatan matrik ternormalisasi terbobot. Matrik keputusan ternormalisasi terbobot didapatkan dari hasil perkalian matrik yang sebelumnya sudah ternormalisasi dengan mutu preferensi seperti pada tabel 6 dan 9. Perhitungan matrik ternormalisasi terbobot sebagai berikut : Nilai kolom $\mathrm{C} 1$ baris $\mathrm{C} 1=0,239$ x 3,359 $=0,802$

Selanjutnya menghitung keseluruhan nilai, dan hasilnya ialah sebagai berikut :

Tabel 10. Matrik Ternormalisasi Terbobot

\begin{tabular}{|l|l|l|l|l|l|}
\hline Alternatif & C1 & C2 & C3 & C4 & C5 \\
\hline Alternatif 1 & 0,803 & 1,256 & 0,439 & 0,224 & 0,176 \\
\hline Alternatif 2 & 1,606 & 0,942 & 0,585 & 0,373 & 0,035 \\
\hline Alternatif 3 & 2,007 & 0,942 & 0,585 & 0,149 & 0,106 \\
\hline Alternatif 4 & 1,204 & 1,570 & 0,439 & 0,149 & 0,141 \\
\hline Alternatif 5 & 1,606 & 1,570 & 0,585 & 0,373 & 0,070 \\
\hline
\end{tabular}

Selanjutnya dari hasil matrik diatas dapat dilanjutkan dengan penentuan penyelesaian solusi ideal negatif dan positif. Sebelum mencari penyelesaian solusi ideal negatif dan positif mesti menentukan nilai-nilai minimal dan maksimal dari tiap kolom.

Tabel 11. Matrik Ternormalisasi Terbobot

\begin{tabular}{|l|l|l|l|l|l|}
\hline Alternatif & C1 & C2 & C3 & C4 & C5 \\
\hline Alternatif 1 & 0,803 & 1,256 & 0,439 & 0,224 & 0,176 \\
\hline Alternatif 2 & 1,606 & 0,942 & 0,585 & 0,373 & 0,035 \\
\hline Alternatif 3 & 2,007 & 0,942 & 0,585 & 0,149 & 0,106 \\
\hline Alternatif 4 & 1,204 & 1,570 & 0,439 & 0,149 & 0,141 \\
\hline Alternatif 5 & 1,606 & 1,570 & 0,585 & 0,373 & 0,070 \\
\hline Max & 2,007 & 1,570 & 0,585 & 0,373 & 0,176 \\
\hline Min 0,803 & 0,942 & 0,439 & 0,149 & 0,035 \\
\hline
\end{tabular}

$$
\begin{aligned}
& =\sqrt{\begin{array}{c}
\left((0,803-2,007)^{2}+(1,256-1,570)^{2}+\right. \\
(0,439-0,585)^{2}+(0,224-0,373)^{2}+ \\
(0,176-0,176)^{2}
\end{array}} \\
D+ & =1,262
\end{aligned}
$$


$\mathrm{D}$ -

$\mathrm{D}-=0,352$

Selanjutnya menghitung keseluruhan nilai, dan hasilnya ialah sebagai berikut :

Tabel 12. Alternatif D+ dan D-

\begin{tabular}{|l|l|l|}
\hline Alternatif & D+ & D- \\
\hline Alternatif 1 & 1,262 & 0,352 \\
\hline Alternatif 2 & 0,759 & 0,846 \\
\hline Alternatif 3 & 0,670 & 1,215 \\
\hline Alternatif 4 & 0,847 & 0,753 \\
\hline Alternatif 5 & 0,415 & 1,054 \\
\hline
\end{tabular}


Selanjutnya adalah mencari nilai akhir atau preferensi (vi) untuk setiap alternatif menggunakan persamaan 13.

Nilai akhir $=\frac{0,352}{0,352+1,262}=0,218$

Selanjutnya menghitung keseluruhan nilai, dan hasilnya ialah sebagai berikut :

Tabel 13. Hasil Akhir

\begin{tabular}{|l|l|l|}
\hline Alternatif & Nilai & Rangking \\
\hline Alternatif 1 & 0,218 & 5 \\
\hline Alternatif 2 & 0,527 & 3 \\
\hline Alternatif 3 & 0,645 & 2 \\
\hline Alternatif 4 & 0,471 & 4 \\
\hline Alternatif 5 & 0,718 & 1 \\
\hline
\end{tabular}

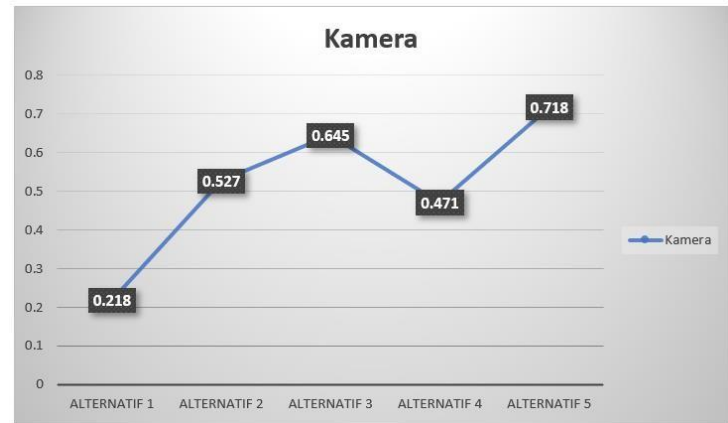

Gambar 3. 1 Grafik Hasil Perhitungan

Jadi dari nilai yang diperoleh nilai A5 adalah nilai terbesar, sehingga Alternatif 5 dipilih sebagai pemilihan kamera DSLR terbaik. 


\section{HASIL DAN PEMBAHASAN}

\section{Perancangan Unified Modelling Language}

(UML)

\section{vUsecase Diagram}

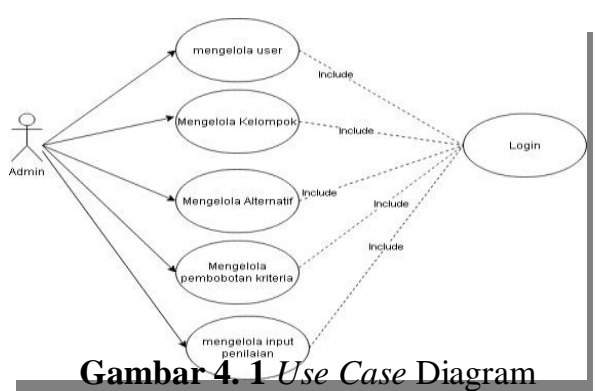

\section{Activity Diagram}

Activity Diagram Login

Activity login adalah untuk mengetahui berjalannya aplikasi login

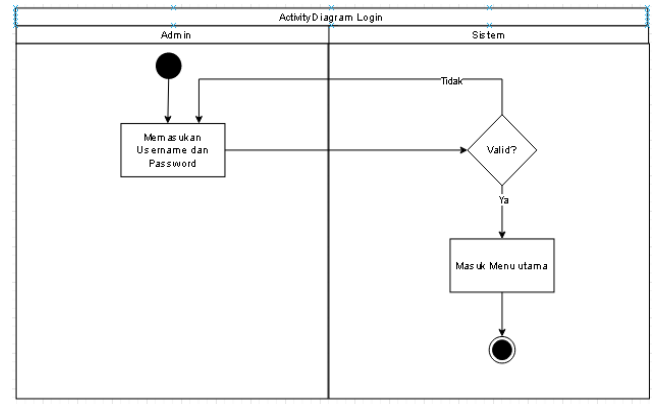

Gambar 4. 2 Login Activity 
Activity diagram Manajemen User Merupakan aktivitas dari menu manejmen user menyediakan fitur tambah, ubah, hapus yang dapat dipilih untuk kelola data

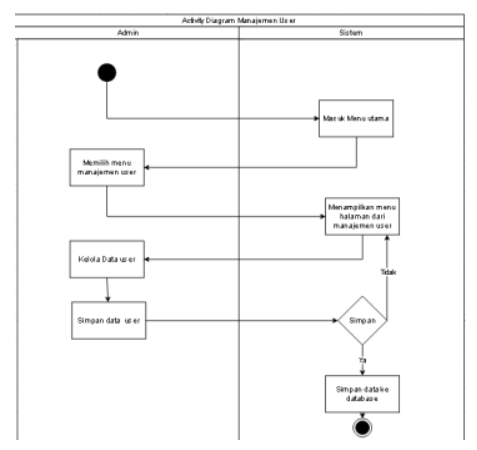

Gambar 4. 3 Activity menu manajemen user

Activity Diagram kelompok

Merupakan aktivitas dari menu kelompok menyediakan fitur tambah, ubah, hapus yang dapat dipilih untuk kelola data

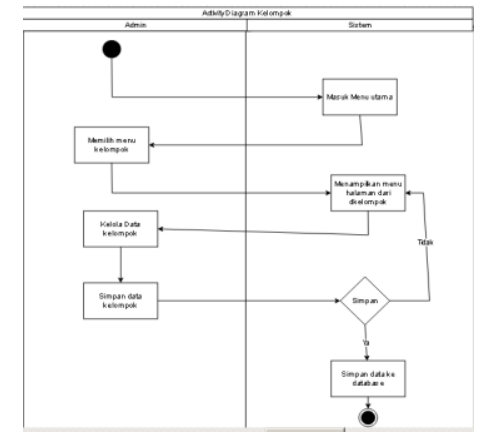

Gambar 4. 4 Activity Diagram kemlompok

Activity Diagram Alternatif

Merupakan aktivitas dari menu Alternatif menyediakan fitur tambah, ubah, hapus yang dapat dipilih untuk kelola data

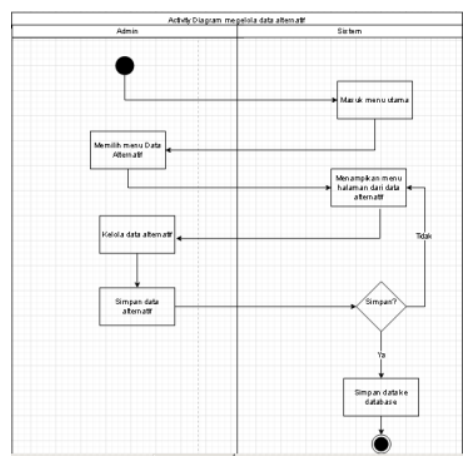

Gambar 4. 5 Activity Diagram Menu Alternatif 
Activity diagram Kriteria

Merupakan aktivitas dari menu kriteria menyediakan fitur tambah, ubah, hapus yang dapat dipilih untuk kelola data

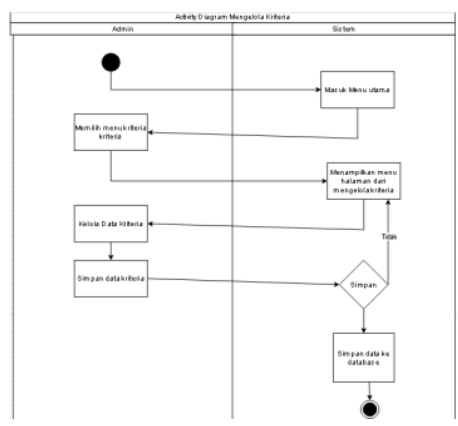

Gambar 4. 6 Activity Diagram Menu kriteria

Activity diagram bobot kriteria

Merupakan aktivitas dari menu bobot kriteria

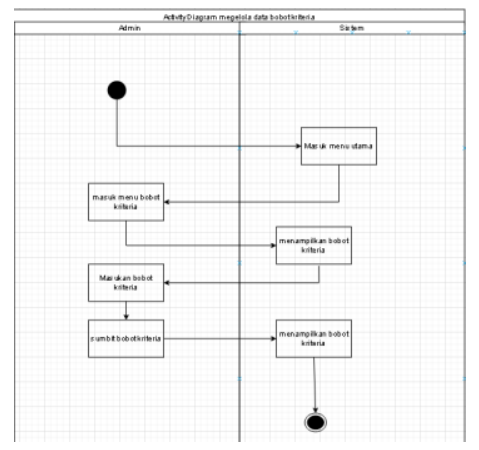

Gambar 4. 7 Activity Diagram menu bobot kriteria

Activity Diagram InputPenilaian

Merupakan aktivitas dari menu menyediakan fitur ubah yang dapat dipilih untuk kelola data

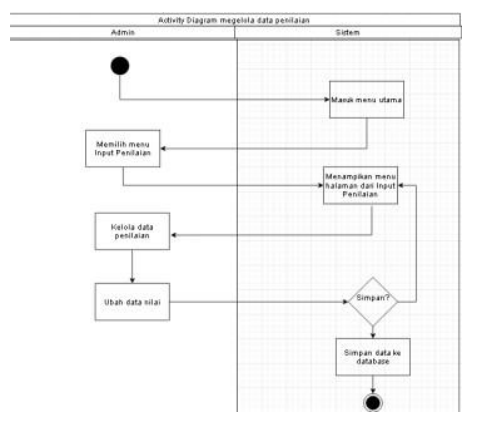

Gambar 4. 8 Activity Diagram Penilaian 
Activity Diagram hasil

Merupakan aktivitas dari menu manejmen user menyediakan tampilkan untuk menampilkan data

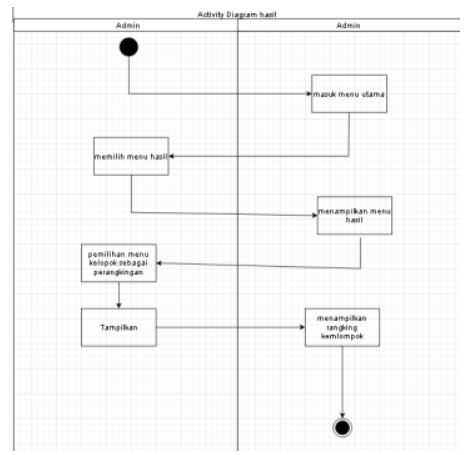

Gambar 4. 9 Activity Diagram Hasil

\section{Sequance Diagram}

Sequence diagram ada lah diagram yang menunjukan rentang waktu jalannya aplikasi

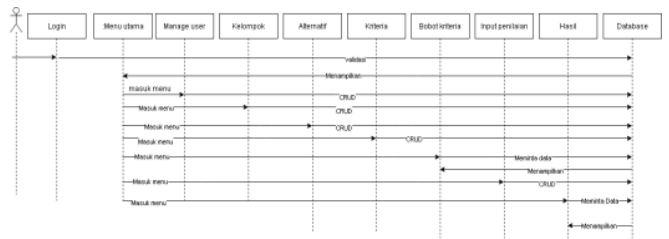

Gambar 4. 10 sequence Diagram 
Implementasi Program

\section{Halaman Login}

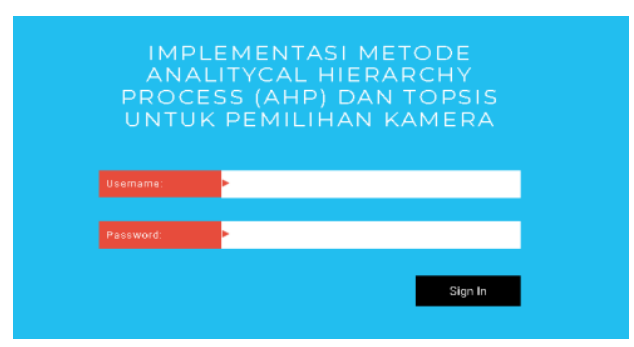

Gambar 4. 11 Halaman Login

Halaman Dashboard

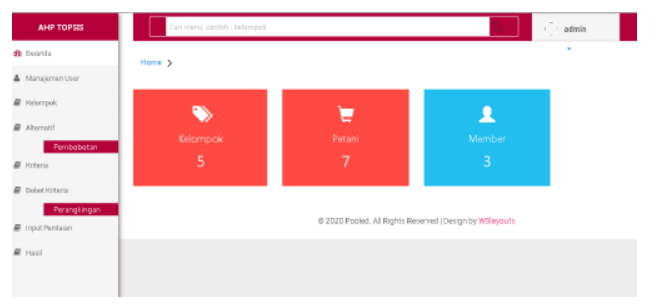

Gambar 4. 12 Halaman Dashboard 


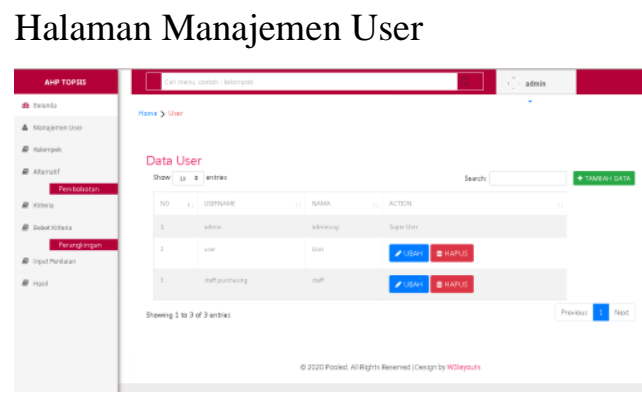

Gambar 4. 13 Halaman Manajemen User

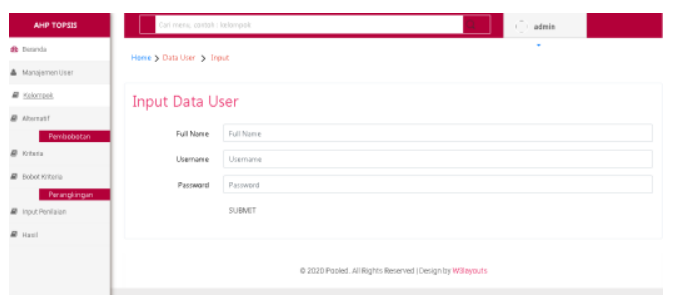

Gambar 4. 14 Halaman tambah Manajemen User

Halaman Kelompok

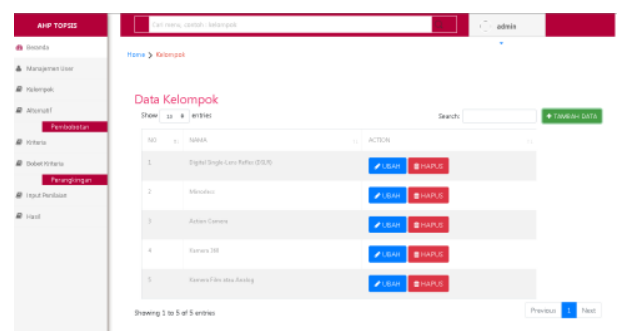

Gambar 4. 15 Halaman Kelompok

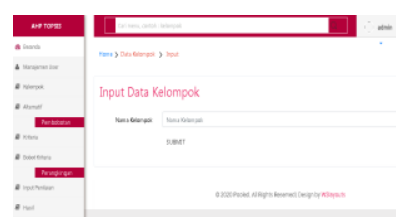

Gambar 4. 16 Halaman Tambah Kelompok

Halaman Alternatif

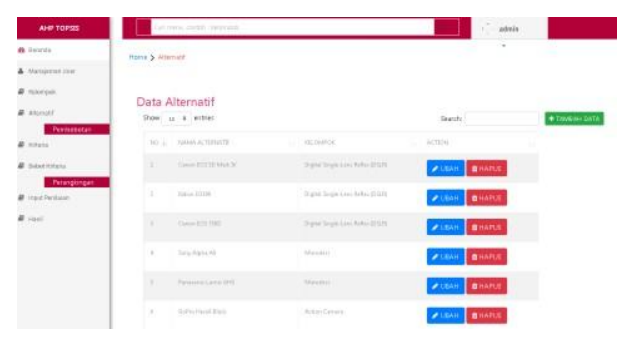


Gambar 4. 17 Halaman Alternatif

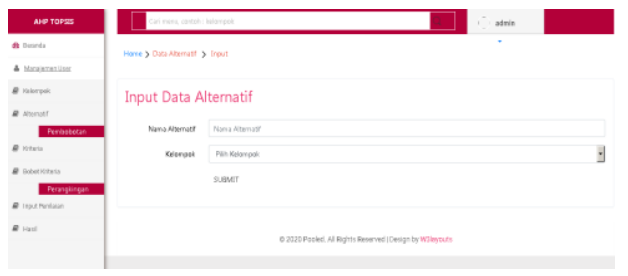

Gambar 4. 18 Halaman tambah alternatif

Halaman Kriteria

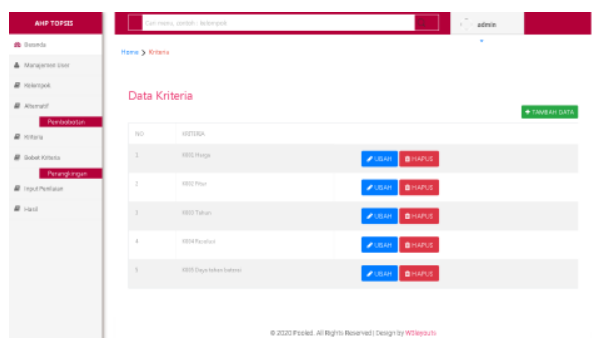

Gambar 4. 19 Halaman Kriteria

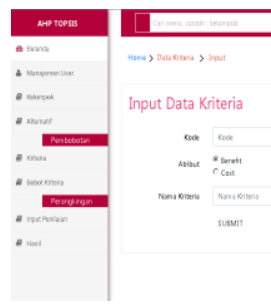

Gambar 4. 20 Halaman tambah Kriteria

Halaman Bobot Kriteria

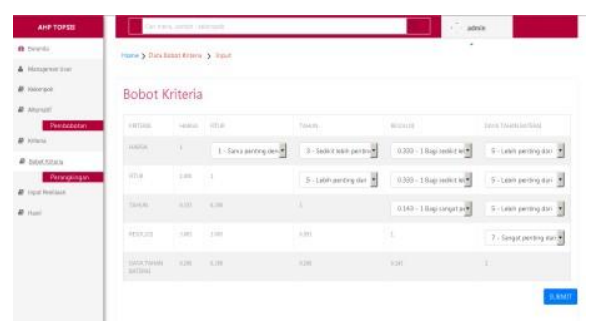

Gambar 4. 21 Halaman Bobot Kriteria

Halaman Input Penilaian 
Jurnal Teknik Informatika dan Sistem Informasi

Vol. 8, No. 1, Maret 2021, Hal. 401-420

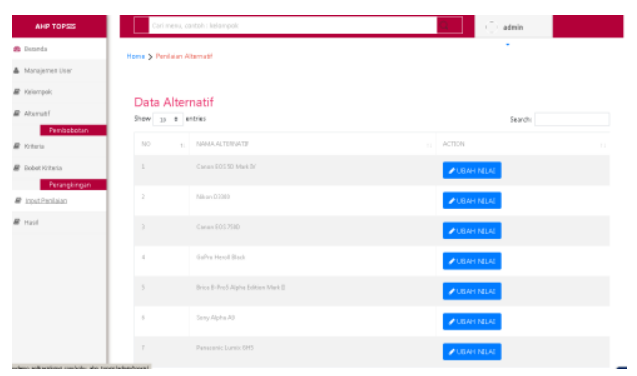

Gambar 4. 22 Halaman Input Penilaian

Halaman Hasil

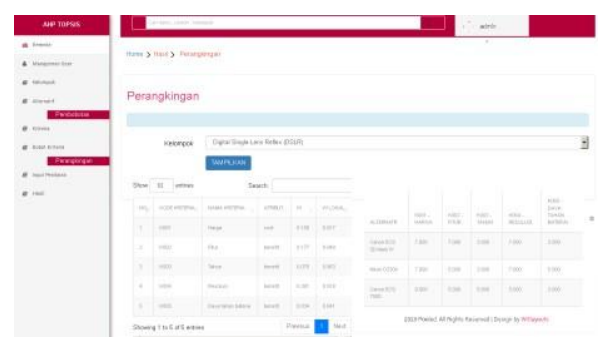

Gambar 4. 23 Halaman Hasil
ISSN 2407- 4322

E- ISSN 2503-2933 


\section{Pengujian Blackbox Testing}

Tabel 4. 1 Pengujian Blackbox Testing

\begin{tabular}{|c|c|c|c|c|}
\hline No & Halaman Uji & Cara Pengujian & $\begin{array}{l}\text { Hasil Yang } \\
\text { Diharapkan }\end{array}$ & Status \\
\hline 1. & Halaman Login & $\begin{array}{l}\text { 1.Pengguna memasukan } \\
\text { username dan password }\end{array}$ & $\begin{array}{l}\text { Berhasil masuk } \\
\text { kedalam sistem }\end{array}$ & Sukses \\
\hline 2. & Halaman Dashboard & $\begin{array}{l}\text { 1. Pengguna membuka halaman } \\
\text { sistem }\end{array}$ & $\begin{array}{l}\text { Berhasil menampilkan } \\
\text { halaman dashboard }\end{array}$ & n Sukses \\
\hline 3. & Halaman Manajemen user & $\begin{array}{l}\text { Buka menu data manajemen user } \\
\text { Melakukan penambahan user } \\
\text { 3.Melakukan edit user } \\
\text { 4.Melakukan delete user }\end{array}$ & $\begin{array}{l}\text { Berhasil menampilkan } \\
\text { data yang diminta }\end{array}$ & n Sukses \\
\hline 4. & Halaman kelompok & $\begin{array}{l}\text { 1. Buka menu data kelompok } \\
\text { 2.Melakukan penambahan data } \\
\text { kelompok } \\
\text { 3.Melakukan edit data kelompok } \\
\text { 4.Melakukan delete data } \\
\text { kelompok }\end{array}$ & $\begin{array}{l}\text { Berhasil menampilkan } \\
\text { data yang diminta }\end{array}$ & n Sukses \\
\hline 5. & Halaman Alternatif & $\begin{array}{l}\text { Buka menu data alternatif } \\
\text { Melakukan penambahan alternatif } \\
\text { Melakukan edit alternatif } \\
\text { 4.Melakukan delete alternatif }\end{array}$ & $\begin{array}{l}\text { Berhasil menampilkan } \\
\text { data yang diminta }\end{array}$ & n Sukses \\
\hline 6. & Halaman kriteria & $\begin{array}{l}\text { Membuka menu kriteria } \\
\text { Melakukan penambahan kriteria } \\
\text { Melakukan edit kriteria } \\
\text { 4.Melakukan delete kriteria }\end{array}$ & $\begin{array}{l}\text { Berhasil } \\
\text { Menampilkan data } \\
\text { yang diminta }\end{array}$ & Sukses \\
\hline 7. & Halaman Bobot kriteria & $\begin{array}{l}\text { Dapat menampilkan bobot kriteria } \\
\text { Dapat melakukan submit untuk } \\
\text { pencarian bobot kriteria }\end{array}$ & $\begin{array}{l}\text { Menampilkan data } \\
\text { yang diminta }\end{array}$ & Sukses \\
\hline 8 & Halaman Input penilaian & $\begin{array}{l}1 \text { menampilkan halaman input } \\
\text { nilai. } \\
\text { 2. dapat mengubah nilai data }\end{array}$ & $\begin{array}{l}\text { Berhasil } \\
\text { menampilkan data } \\
\text { yang diminta }\end{array}$ & sukses \\
\hline 9 & Halaman hasil & $\begin{array}{l}\text { Dapat menampilkan halaman dari } \\
\text { hasil } \\
\text { Dapat menampilkan } \\
\text { perangkingan dari jenis yang di } \\
\text { cari }\end{array}$ & $\begin{array}{l}\text { Dapat menampilkan } \\
\text { data yang diminta }\end{array}$ & sukses \\
\hline
\end{tabular}




\section{KESIMPULAN DAN SARAN}

\section{KESIMPULAN}

Kesimpulan dari penelitian ini adalah peneliti berhasil membangun sistem pendukung keputusan pemilihan kamera DSLR menggunakan metode AHP dan TOPSIS.

Metode ini dapat diimplementasikan dengan baik pada aplikasi web dan dapat membantu proses pengambilan keputusan pemilihan kamera secara lebih akurat.

Saran dari penelitian ini adalah sistem pendukung keputusan pemilihan kamera ini dapat ditanamkan pada sistem e-commerce.

TERIMA KASIH KEPADA warga setempat yang telah memberikan dukungan financial terhadap penelitian ini. 


\section{DAFTAR PUSTAKA}

[1] Agustino, A., Suyatno, A., \& Astuti, I. F. (2016). Sistem Pendukung Keputusan Pemilihan Kamera Digital single Lens Reflex Menggunakan Metode Elimination Et Choix Traduisant La Realite (ELECTRE). Informatika Mulawarman: Jurnal IImiah Ilmu Komputer, 9(2), 1-6.

[2] Mu'amalah, I., \& Meydiana, A. (2019). Implementasi Fuzzy Mamdani dalam Sistem Pendukung Keputusan Pemilihan Kamera DSLR bagi Pemula. SIMETRIS, 13(1), 1-5.

[3] Rouhani, S. "Evaluation model of business intelligence for enterprise systems using fuzzy TOPSIS". Expert System with Applications. 2012. ISSN : 0957-4174.

[4] Anhar, A. "Kombinasi Metode TOPSIS (Technique for Order Preference by Similarity to Ideal Solution) dan AHP (Analytical Hierarchy Process) dalam Menentukan Objek Wisata Terbaik di Pulau Bali". Jurnal Mahasiswa Matermatika. 2013. ISSN : 2502-7204.

[5] Arbelia, Paryanta. "Penerapan Metode AHP dan Topsis Sebagai Sistem Pendukung Keputusan Dalam Menentukan Kenaikan Jabatan Bagi Karyawan". Jurnal IImiah Go Infotech Vol. 02, No. 1, Juni 2014. ISSN : 1693-5902.

[6] T. L. Saaty, "Decision Making with the Analytic Hierarchy Process", International Jurnal services science. 2008. ISSN : 2345- 3605.

[7] Turban, E. "Decision Support System and Intelligent System". Prentice Hall International. 1998.

[8] C. a. M. B. Holmes, "Generalized Nonlinear Modeling with Multivariate Free-Knot Regression Spline.", Journal of the American Statistical Association, Vol. 98, No. 462, pp. 352-365., 2003.

[9] I. T. Sevandri, R. K. Dewi and M. T. Ananta, "Implementasi Algoritma Topsis Pada Sistem Rekomendasi Pencarian Lokasi Gym Berbasis Android (Studi Kasus: Kota Malang)," 2019

[10] A. P. Windarto, "IMPLEMENTASI METODE TOPSIS DAN SAW DALAM MEMBERIKAN REWARD PELANGGAN," 2017

[11] A. Y. PUTRI, "IMPLEMENTASI ALGORITMA AHP DAN SAW UNTUK PENILAIAN KINERJA PEGAWAI PADA 
APLIKASI KEPEGAWAIAN (STUDI KASUS KANTOR PPDPP)," 2019.

[12] M. HUJATULLOH, "IMPLEMENTASI ALGORITMA ANALITYCAL HIERARCHY PROCESS (AHP) PADA APLIKASI PENGAMBILAN KEPUTUSAN PENILAIAN KINERJA KARYAWAN BERBASIS WEB PADA PT XYZ," 2019.

[13] S. A. Kusumastuti, "Implementasi Algoritma Analytical Hierarchy Process (AHP) Dalam Menentukan Peringkat Gizi Balita Pada Aplikasi SIPPO (Studi Kasus: Posyandu Permatasari)," 2017.

[14] N. F. Ganies, D. E. Ratnawati and B. Rahayudi, "Implementasi Algoritma Genetika Pada Metode AHP dan SAW untuk Rekomendasi Varietas Unggul Tanaman Tebu (Studi Kasus: Pusat Penelitian Gula PTPN X Jengkol)," 2017.

[15] D. A. a. Y. Y. a. R. D. RIZALDI, "IMPLEMENTASI METODE ANALYTICAL HIERARCHY PROCESS (AHP) DAN TECHINIQUE FOR ORDER OF PREFERENCE BY SIMILARITY TO IDEAL SOLUTION (TOPSIS) DALAM SISTEM PENDUKUNG KEPUTUSAN UNTUK PEMBELIAN MOBIL PADA RENTAL MOBIL," 2020.

[16] I. Hamdhani, N. Hidayat and I. Cholissodin, "Sistem Pendukung Keputusan Penentuan Kelayakan Kandang Ayam Broiler Menggunakan Metode Analytic Hierarchy Process-Weighted Product (AHP-WP) [Studi Kasus PT. Semesta Mitra Sejahtera Wilayah Jombang, Kediri, dan Tulungagung]," 2017.

[17] D. R. Bahari, E. Santoso and S. Adinugroho, "Sistem Pendukung Keputusan Penentuan Guru Berprestasi Menggunakan Fuzzy- Analytic Hierarchy Process (F-AHP) (Studi Kasus : SMA Brawijaya Smart School)," 2017.

[18] M. Mupidah, "IMPLEMENTASI METODE PROFILE MATCHING DAN ANALYTICAL HIERARCHI PROCESS (AHP) PADA PEREKRUTAN TENAGA KURIR," 2019.

[19] A. P. Wasnardi and A. Kodar, "Implementasi Algoritma Analytical Hierarchy Process Pada Aplikasi loT," 2019.

[20] R. D. Heriyantoro, . M. . I. Dzulhaq and L. S. Mawarni Silitonga, "SISTEM PENDUKUNG KEPUTUSAN PENENTUAN GURU BERPRESTASI DENGAN METODE AHP DAN SAW PADA SMA MARKUS TANGERANG," 2020. 